\title{
ASSESSMENT OF HEALTH RELATED QUALITY OF LIFE IN PAEDIATRIC PATIENTS WITH ASTHMA - METHODS AND DISEASE DETERMINANTS
}

\author{
Anna Todorova $^{1}$, Antoaneta Tzvetkova ${ }^{2}$, Iskra Mircheva ${ }^{3}$ \\ ${ }^{1}$ Faculty of Pharmacy, Medical University of Varna \\ ${ }^{2}$ Medical College, Medical University of Varna \\ ${ }^{3}$ Faculty of Public Health, Medical University of Varna
}

\begin{abstract}
The purpose of this article is to provide an overview of the methods for assessing Health Related Quality of Life (HRQOL) in children with a focus on both the instruments available for measuring HRQOL in pediatric patients with asthma and the disease determinants. Adolescents with bronchial asthma often have substantially lower HRQOL. Frequent exacerbations impair children's normal daily routines such as school activities, play and sleep. The factors affecting children's HRQOL largely vary from those affecting the HRQOL in adults. Chronic diseases in childhood are a risk factor associated with serious psychosocial consequences low self-esteem, behavioral problems, and difficulties in learning. Assessment of HRQOL can be successfully integrated in achieving the primary aim of the disease management - to maintain health as a state of complete physical, mental and social well-being.
\end{abstract}

Keywords: Health Related Quality of Life, assessment, children, asthma, disease determinants

\section{INTRODUCTION}

"Quality of Life" (QOL) is a concept widely used to refer to the subjective well-being of individuals. There is no clearly defined and agreed-upon definition of QOL. The term "Quality of Life" is used to refer to individuals' subjective satisfaction with important aspects of their life - their physical and mental well-being, social relationships, social and individual activities, individual satisfaction, and health maintenance (8). QOL refers to all aspects of human life, in-

Address for correspondence:

Anna Todorova

Faculty of Pharmacy, Medical University - Varna

55 Marin Drinov Str.

9002 Varna, Bulgaria

e-mail:annitodorova@abv.bg

Received: July 23, 2015

Accepted: December 1, 2015 cluding environmental factors outside the context of health care. QOL is a broad term that takes into account a wide range of information and refers to various aspects of the life style of individuals and their corresponding subjective assessment. The term encompasses the following essential aspects:

* occupation and vocation;

* financial well-being;

* family;

* community integration and social inclusion;

* health status and health care;

* education and training (19).

There are many interdependent QOL-related factors, e.g. financial and nonfinancial, health status etc. One of the QOL-related components is the health-related quality of life (HRQL). It is based on the definition provided by the World Health Organization (WHO). The Constitution of WHO (1946) states that "health is a state of complete physical, mental and social well-being and not merely the ab- 
sence of disease or infirmity" (22). HRQOL depends on patient's self-perception and evaluation of disease-related impairment and measures the impact of the impairment on patient's QOL. Schipper's definition states that "HRQL can be defined as the functional effect of an illness and its consequent therapy upon a patient, as perceived by a patient" (30). HRQOL focuses on the individual satisfaction with those aspects that are both influenced by and affecting individuals' health, e.g. their functional status (physical activity, mobility, self-maintenance), emotional health (anxiety, stress, depression), social functioning (social relationships, daily activities at work and at home), long-lasting symptoms, life satisfaction (18). In the sphere of health care, HRQOL is employed in the studies of medical interventions, epidemiological studies, pharmacoeconomic evaluations (cost-effectiveness and cost-benefit analyses) (19). Studies on HRQOL are essential for evaluating the therapeutic effectiveness and achieving the primary goal of disease management, which is to maintain health as a state of complete physical, mental and social well-being.

\section{AIM}

The aim of this article is to provide an overview of the methods for assessing the HRQOL in children with a focus on both the available instruments and the determinant factors of HRQOL in paediatric patients with asthma.

\section{MATERIAL AND METHODS}

An overview of literature sources and scientific researches is given to explore the generic methods for assessing the HRQOL in children. Furthermore, the overview offers an analysis of the disease-specific methods for assessing the HRQOL in children with asthma. The information was collected from various electronic databases (Pubmed, Scopus, Medline, etc.) with the help of a set of predefined keywords: asthma, children, HRQOL, instruments. As a result, generic and specific assessment instruments are differentiated. Based on the available research results, the determinants of HRQOL in paediatric patients with asthma are defined.

\section{Assessing HRQOL}

A wide range of various standardized assessment methods can be used for HRQOL assessment.
There is a database with about 700 instruments for assessing the HRQOL in different population groups (33). Regardless of the underlying general health concept provided by $\mathrm{WHO}$, there are variations in the different assessment instruments, as a result of which the physical and emotional health is often poorly defined. The lack of a well-developed common definition for HRQOL poses a challenge for the accurate assessment and interpretation of the results. Research sources indicates that controversial issues are the age at which children can provide a reliable HRQOL selfassessment, the validity of their assessment, and the role of their parents in the questionnaire administration $(15,38)$. Some studies have found that children aged over 5 years can give an accurate subjective assessment with the help of suitable survey in struments. It is recommendable that parents are included as respondents to validate the results and provide additional information for children under the age of 9 (38).

Depending on the specificity of the survey instrument, there are two main groups of HRQOL measures: generic and disease-specific.

Generic instruments encompass all aspects of HRQOL and provide a comparison between the HRQOL in healthy individuals and those with chronic diseases, as well as between patients with different diseases (19).

Disease-specific instruments are sensitive to subtle but significant individual disease variations that cannot be detected by generic tools. HRQOL disease-specific instruments have been developed for the assessment of a medical condition or a therapeutic regimen in patients with chronic diseases (19).

Differences in values, beliefs and perceptions of people with various diseases, distinct background and culture underlie the development of different tools for HRQOL assessment. The fundamental issue in selecting a HRQOL assessment instrument is its reliability and validity for the surveyed population group.

Some authors assume that the instruments chosen for the assessment of HRQOL in children should have the following characteristics: 1) a clear and practical conceptualization of HRQOL which might greatly affect the type of selected instruments; 2) relevance to the theoretical principles of pediat- 
ric HRQOL with regards to the specific assessment process and its interpretation by pediatric patients; 3) the instruments should encompass important aspects of the children's lives that evidently affect the evaluation and interpretation of results; and 4) the separate elements should be suitably assembled since their wording directly influences the answers given by children. However, the instruments available for HRQOL assessment rarely have the above mentioned characteristics. Furthermore, very little of the available tools for the assessment of pediatric HRQOL are based entirely on the theoretical principles (5).

Generic instruments for pediatric HRQOL assessment are used for the evaluation of children's physical, mental and social heath, their family and school environment, the changes in their health status, and the disease-related discomfort and limitations $(2,4,16,23,29)$. The available generic instruments for children are CHQ (Child Health Questionnaire), CATIS (Child Attitude Toward Illness Scale), DisabkidsDCGM (Disabkids Chronic Generic Measure), $\mathrm{KINDL}^{\mathrm{R}}$ (Questionnaire for measuring quality of life in children and adolescents), PEDSQL (Pediatric Quality of Life Inventory 4.0 Generic Core Scales), QOML (Quality of my life questionnaire) - the visual analogue scale for HRQOL assessment.

The main aspects measured by the specific instruments for HRQOL assessment in children with asthma are:

* physical distress and sleep disturbance caused by asthma symptoms;

* limitations of physical activity;

* emotional distress (depression, mood swings, anxiety, fear of experiencing a seizure);

* relationships with parents (parent-child conflicts related to the prevention and control of asthma);

* limitations in social life (relationship with peers, school performance);

* inconvenience caused by the need to control the disease (the regular use of medications, frequent visits to the doctor, injections, blood draw procedures, avoidance of certain foods and types of toys) $(12,37)$.

Below are presented the most commonly used specific questionnaires for the assessment of HRQOL in children with asthma:
* Pediatric asthma quality of life questionnaire (PAQLQ) measures the functional problems (physical, emotional and social) that are most common in children with asthma. It examines three domains - symptoms, limitations in daily activities and emotional state assessed within a period of one week. One week is the period for which children are believed to provide the most accurate and reliable information (9).

* Childhood Asthma Questionnaire (CAQ) assesses the impact of the symptoms, the severity of asthma, and patients' attitudes towards the disease. It has been developed for children in three age groups: 4-7 years, 8-11 years, and 12-16 years.

* About My Asthma Questionnaire is used to determine the number, intensity and type of stress factors associated with asthma (5).

The validation of the assessment instruments shows that children give adequate and precise answers. Minor difficulties may occur only with the youngest children regarding their understanding of the temporal interval "the last week".

The specific questionnaires detect subtle, still important for the patient, changes in HRQOL. Patient-tailored, they are suitable for the assessment of individual clinical outcomes. The generic questionnaires provide a comprehensive HRQOL assessment. They facilitate the comparison between a health condition and the corresponding therapies and, therefore, they can be used for both assessing the impact of a health condition on specific groups of patients and comparing the benefits of different therapeutic approaches. Thus, they can influence the decisionmaking process in disease treatment (19).

\section{Factors affecting $H R Q O L$}

The essential determinants of HRQOL in adult patients are their mental health, chronic diseases, body mass index and physical activity, as well as the disease-related mortality rate, the cost of treatment, and the use of health care services $(7,9,27,28)$.

The factors affecting the HRQOL in children are highly specific. Studies have found that chronic diseases in childhood are a risk factor associated with serious psychosocial consequences - low self-esteem, behavioral problems, and difficulties in learning (17). Some sources report that there is a sig- 
Anna Todorova, Antoaneta Tzvetkova, Iskra Mircheva

nificant correlation between pediatric patients' age and gender and their HRQOL (38). Other authors have established that girls experience lower mental well-being than boys, and older pediatric patients experience better HRQOL than younger pediatric patients (24). Psychological factors, optimism and pessimism are believed to be affecting the HRQOL in both healthy children and those with chronic diseases (39). Overweight, sedentary lifestyle, depression, drowsiness and sleep problems are associated with low HRQOL in adolescents $(33,36)$. A comparative study on the HRQOL in children with dermatological diseases and other chronic diseases has identified that HRQOL is most impaired in children suffering from cerebral paralysis, followed by those with kidney diseases, cystic fibrosis, asthma, urticaria, psoriasis, epilepsy and diabetes. Children with acne, alopecia, and localized eczema experience higher HRQOL in comparison with the rest of the surveyed children with dermatological diseases and other chronic diseases (14).

The dominant theoretical model relates the deterioration of health status to poor HRQOL. However, health status and HRQOL are concepts that cannot be used interchangeably. Studies have provided evidence of drug therapies yielding improved clinical outcomes and, at the same time, no noticeable change in HRQOL (10). Other studies have found self-perceived health effect that has not been detected by the conventional scoring scales (3). Therefore, there is a distinction drawn between the assessment of HRQOL and the assessment of symptoms. Given the specificity of the worldviews and perceptions of children, the distinction is particularly relevant to the assessment of HRQOL in children. The improvement of HRQOL, as perceived by a patient, is associated with the self-assessment of patient's private life and community functioning rather than with the change in the clinical parameters.

Factors influencing the HRQOL in children with asthma

Literary sources indicate that the level of disease control is the main factor influencing the HRQOL in children with asthma. It has been found that children with poorly controlled asthma symptoms experience lower HRQOL $(6,20,21)$.
The systemic corticosteroids use and asthmarelated hospitalizations depend on the level of disease control and affect adversely patients' HRQOL (1). According to some authors, poor disease control in adolescents can affect their emotional, intellectual and physical development (13). A research has provided evidence on the correlation between asthma control and the HRQOL in pediatric patients in two age groups - 6-12 years and 13-16 years. The findings indicate a statistically significant moderate correlation between the level of asthma control and patients' HRQOL in the first of the surveyed groups. In the second group, there is a statistically significant strong correlation between the two variables (34). According to some authors, asthma-related cough affects the HRQOL in children aged 8-14, girls particularly, more than any other asthma symptom (21). It has been found that the limitations in physical activities (mainly running) affect patients' HRQOL more than the disease symptoms and patients' emotional wellbeing (26). Other studies have established variations in pediatric HRQOL by age and gender $(25,38)$. The analysis with the generic instrument CATIS in the age groups 6-12 and 13-16 has indicated a statistically significant correlation between patients' HRQOL and their age and gender. The increasing age is associated with a decrease in patients' HRQOL. The study has evidenced that teenagers are more prone to disease-related depression. The results suggest that the reduced HRQOL and the strong correlation between the measured variable and patients' age result from patients' growing awareness of the chronic nature of their disease and the related limitations. The survey findings show that girls report HRQOL lower than the HRQOL reported by boys (35).

Regardless of the disease-related discomforts and limitations in patients with asthma, the assessment scale of the survey instrument has not indicated a negative attitude in the surveyed children' toward their disease or lower values in their HRQOL (35). Children's perceptions of the world are specific and, unlike adult patients with asthma, they do not take much notice of sleep disturbances, they are less affected by disease-related emotional issues, and their daily activities are less impaired (32). There is evidence that the subjective HRQOL is far more complex than the simple measurement of patients' physical, emotional and social functions (31). 


\section{CONCLUSION}

Both paediatric patients and their parents or caregivers can provide valuable and relevant information for the assessment of HRQOL in childhood. Therefore, survey tools need to be designed in a way suitable for adults and children alike.

In the assessment of paediatric HRQOL, the specific questionnaires have proven to be less discriminative and evaluative than the generic ones. They are adjusted to the specific health conditions and are suitable for the assessment of disease specific changes. However, generic questionnaires can provide a comparison between distinct population groups, as well as between healthy individuals and those with impaired health.

The assessment of HRQOL in children and their health status is a complex and multi-faceted process. Patients view their HRQOL and their health status as two distinct concepts. It holds true for paediatric patients as well, regardless of their specific perceptions of the world. Patients' mental health has a much greater impact on their quality of life than their physical functions, whereas the health status is more closely associated with the concept of health.

The instruments for assessing HRQOL are widely used in disease management and research work. Though they have proved to be applicable in disease therapy and scientific work, they need further sophistication to provide better therapeutic outcomes and better understanding of the interdependencies of all the variables that define the HRQOL, as perceived by the patients.

\section{REFERENCES}

1. Al-Gewely MS, El-Hosseiny M, Abou Elezz NF, ElGhoneimy DH, Hassan AM. Health-related quality of life in childhood bronchial asthma. Egypt J Pediatr Allergy Immunol. 2013;11(2):83-93.

2. Austin JK, Huberty TJ. Development of the Child Attitude Toward Illness Scale. Journal of Pediatric Psychology. 1993;18:467-480.

3. Ciprandi G, Canonica WG, Grosclaude M, Ostinelli J, Brazzola G, Bousquet J. Effects of budesonide and fluticasone propionate in a placebo - controlled study on symptoms and quality of life in seasonal allergic rhinitis. Allergy. 2002;57:586-591.
4. Chaplin JE, Hanas R, Lind A, Tollig H, Wramner N, Lindblad B. Assessment of childhood diabetesrelated quality-of-life in West Sweden. Acta Paediatrica. 2008;98:361-366.

5. Davis E, Waters E, Mackinnon A, Reddihough D, Graham K, Mehmet-Radji O, et al. Paediatric quality of life instruments: a review of the impact of the conceptual framework on outcomes. Developmental Medicine \& Child Neurology. 2006;48:311-318.

6. Everhart RS, Fiese BH. Asthma severity and child quality of life in pediatric asthma: a systematic review. Patient Education and Counseling. 2009;75(2):162-168.

7. Garner E, Feeny H, Thompson A, Bernier J, McFarland $\mathrm{H}$, Huguet N, et al. Bodyweight, gender, and quality of life: a population-based longitudinal study. Quality of Life Research. 2012;21(5):813-825.

8. Haas BK. Clarification and Integration of Similar Quality of Life Concepts. Journal of Nursing Scholarship. 1999;31(3):215-220.

9. Kaplan MS, Berthelot JM, Feeny D, McFarland $\mathrm{BH}$, Khan S, Orpana $\mathrm{H}$. The predictive validity of health-related-quality-of-life measures: mortality in longitudinal population-based study. Quality of Life Research. 2007;16(9) : 1539-1546.

10. Kremer B. Quality of life scales in allergic rhinitis. Curr Opin Allergy Clin Immunol. 2004;4:171-176.

11. Laaksonen C. Health-related quality of life in scool children. Validation of Instrument, Child Self Assessment, Parent-Proxy Assessment and School Nursing Documentation of Health Checkups. Turun Yliopisto. University of Turku. Turku, Finland, 2012.

12. Chiang LC. Exploring the Health-Related Quality of Life Among Children With Moderate Asthma. Journal of Nursing Research. 2005;1(13):137-143.

13. Lowe L, Custovic A, Woodcock A. Childhood asthma. Curr Allergy Asthma Rep. 2004;4:159-165.

14. Marklund B, Ahlstedt S, Nordström G. Health-related quality of life in food hypersensitive school children and their families: parents' perceptions. Health and Quality of Life Outcomes. 2006;4:48.

15. Matza LS, Swensen AR, Flood EM, Secnik K, Leidy NK. Assessment of Health-Related Quality of Life in Children: A Review of Conceptual, Methodological, and Regulatory Issues. Value Health. 2004;7(1):79-92. 
Anna Todorova, Antoaneta Tzvetkova, Iskra Mircheva

16. Milde-Busch A, Heinrich S, Thomas S, Kuhnlein A, Radon K, Straube A, et al. Quality of life in adolescents with headache: results from a populationbased survey. Cephalagia. 2010;30:713-721.

17. Okelo SO, Wu AW, Krishnan JA, Rand CS, Skinner EA, Diette GB Emotional quality-of-life and outcomes in adolescents with asthma. J Pediatr. 2004;145: 523- 529.

18. Patrick DL. Patient-reported outcomes (PRO's): an organizing tool for concepts, measures, and applications. Quality of Life Newsletter. 2003;31:1-5.

19. Petrova G. Pharmacoeconomics. Sofia: Infofarma; 2010.

20. Petsios K, Priftis K, Tsoumakas C, Hatziagorou E, Tsanakasand J, Matziou V. Quality of Life in Greek Children with Asthma. Pediatric Research. 2010;68:25-26.

21. Petsios KT, Priftis KN, Tsoumakas C, Perperoglou A, Hatziagorou E, Tsanakas JN, et al. Cough affects quality of life in asthmatic children aged 8-14 more than other asthma symptoms. Allergol Immunopathol. 2009; 37(2):80-88.

22. Preamble to the Constitution of the World Health Organization as adopted by the International Health Conference, New York, 19-22 June, 1946; signed on 22 July 1946 by the representatives of 61 States (Official Records of the World Health Organization, no. 2, p. 100) and entered into force on 7 April 1948.

23. Ravens-Sieberer U, Erhart M, Wille N, Bullinger M. Health-related quality of life in children and adolescents in Germany: results of the BELLA study. Eur Child Adolesc Psychiatry. 2008;17:148-156.

24. Reinfjell T, Diseth TH, Veenstra M, Vikan A. Measuring health-related quality of life in young adolescents: reliability and validity in the Norwegian version of the Pediatric Quality of Life Inventory 4.0 (PedsQL) generic core scales. Health Quality of Life Outcomes. 2006;14(4):61-70.

25. Russell KM, Hudson M, Long A, Phipps S. Assessment of health-related quality of life in children with cancer: consistency and agreement between parent and child reports. Cancer. 2006;106(10):2267-2274.

26. Rydström I, Dalheim-Englund AC, Holritz-Rasmussen B, Möller C, Sandman PO. Asthmaquality of life for Swedish children. J Clin Nurs. 2005;14(6):739-749.
27. Saharinen T, Hintikka J, Kylmä J, KoivumaaHonkanen H, Honkalampi K, Lehto S. Population-Based Comparison of Health-Related Quality of Life Between Healthy Subjects and Those With Specific Psychiatric or Somatic Diseases. Perspectives in Psychiatric Care. 2010;47:66-73.

28. Salaffi F, Sarzi-Puttini P, Girolimetti R, Atzeni F, Gasparini S, Grassi W. Health-related quality of life in fibromyalgia patients: a comparison with rheumatoid arthritis patients and the general population using the SF-36 health survey. Clinical and Experimental Rheumatology. 2009;27(5):67-74.

29. Sandberg M, Johannson E, Bjork J, Wettergren L. Health related quality of life related to school attendance in children on treatment for cancer. J Pediatr Oncol Nurs. 2008;25:265-274.

30. Schipper H, Clinch J, Powell V. Definition and conceptual issues. In: Spilker B (editor). Quality of life assessment in clinical trials. New York: Raven Press; 1990. 11-24.

31. Smith KW, Avis NE, Assmann SF. Distinguishing between quality of life and health status in quality of life research: a meta-analysis. Qual Life Res. 1999;8:447-459.

32. Solans M, Pane S, Estrada MD, Serra-Sutton V, Berra S, Herdman M, et al. Health-related quality of life measurement in children and adolescents: a systematic review of generic and disease-specific instruments. Value Health. 2008;11(4):742-764.

33. Swallen KC, Reither EN, Haas SA, Meier AM. Overweight, Obesity, and Health-Related Quality of Life Among Adolescents: The National Longitudinal Study of Adolescent Health. Pediatrics. 2005;115(2):340-347.

34. Todorova A, Tsvetkova A. Study of asthma control and its effect on Quality of Life in pediatric patients. Childhood and Infectious diseases. 2015; $7(1): 3-8$.

35. Todorova A, Tsvetkova A. Asthma Children patients' quality of life. World Journal of Pharmacy and Pharmaceutical Sciences. 2015;4(1):221-228.

36. Tzischinsky O, Shochat T. Eveningness, Sleep Patterns, Daytime Functioning and Quality of Life in Israel Adolescents. Chronobiology International. 2011;28(4):338-343.

37. Van De Ven M, Engels R. Quality of life of adolescents with asthma: The role of personality, coping strategies, and symptom reporting. Journal of Psychosomatic Research. 2011;71:166-173. 
38. Varni JW, Limbers CA, Burwinkle T. How young can children reliably and validly self-report the health-related quality of life? An analysis of 8591 children across age subgroups with the PedsQL ${ }^{\mathrm{Tm}}$ 4.0 Generic Core Scales. Health and Quality of Life Outcomes. 2007;5(1):1-13.

39. Williams NA, Davis G, Hancock M, Phipps S. Optimism and Pessimism in Children with Cancer and Healthy Children: Confirmatory Factor Analysis of the Youth Life Orientation Test and Relations with Health-Related Quality of Life. Journal of Pediatric Psychology. 2010;35(6):672-682. 